\title{
TI.158.1
}

\section{A Brief History}

- PDF: A Brief History

- Text: A Brief History

\section{More Information}

\begin{tabular}{|l|l|}
\hline Repository ID & TI.158.1 \\
\hline Persistent URL & http://doi.org/10.26869/TI.158.1 \\
\hline Title & A Brief History \\
\hline Authors & Ken Klingenstein \\
\hline Sponsor & Internet2 Trust and Identity executive management \\
\hline Review & \\
\hline Status & preserve \\
\hline Publish Date & June 22,2021 \\
\hline DOI & \\
\hline Signature & \\
\hline Deprecated & No \\
\hline Future Review & \\
\hline Supersedes & \\
\hline Format & pdf, text \\
\hline Related Docs & \\
\hline Development Location & \\
\hline IP Framework & CC BY 4.0 \\
\hline Subject Tags & \\
\hline Notes & \\
\hline & \\
\hline
\end{tabular}

